\title{
AVALIAÇÃO dA EFICIÊNCIA dOS PAVIMENTOS PERMEÁVEIS NA REDUÇÃO DE ESCOAMENTO SUPERFICIAL
}

\author{
Paulo Roberto de Araújo, Carlos E. M. Tucci e Joel A. Goldenfum \\ Instituto de Pesquisas Hidráulicas da UFRGS - Porto Alegre - RS \\ Caixa Postal 15029 - CEP 91501-970 - Porto Alegre, RS
}

\section{RESUMO}

A utilização dos pavimentos permeáveis em áreas urbanas visa: reduzir a vazão drenada superficialmente, melhorar a qualidade da água e contribuir para o aumento da recarga de água subterrânea.

Neste estudo foi avaliada a eficiência dos pavimentos permeáveis na redução do escoamento superficial, através de simulações experimentais, comparando o escoamento gerado em diversos tipos de pavimento e no solo compactado. Foram efetuados experimentos utilizando simulador de chuva em módulos de $1 \mathrm{~m}^{2}$, para quatro diferentes tipos de coberturas urbanas: a) terreno existente; b) superfícies semi-permeáveis; c) superfícies impermeáveis e; d) superfícies permeáveis.

$A$ análise comparativa entre os pavimentos permeáveis e os outros tipos de pavimentos permitiu avaliar a redução no escoamento superficial gerado e fornecer elementos para escolha desta solução em diferentes projetos de áreas urbanas, tais como estacionamentos e passeios de áreas públicas e privadas.

\section{INTRODUÇÃO}

A ocupação urbana através de áreas impermeáveis como telhados, passeios, ruas, estacionamentos e outros, altera as características de volume e qualidade do ciclo hidrológico, trazendo como resultado o aumento das enchentes urbanas e a degradação da qualidade das águas pluviais.

A drenagem urbana tem sido desenvolvida com o princípio de drenar a água das precipitações o mais rápido possível para jusante, produzindo aumento da freqüência e magnitude das enchentes. Este aumento traz consigo o acréscimo da produção de lixo e a deteriorização da qualidade da água.

As ações públicas para as soluções desses problemas no Brasil estão voltadas, na maioria das vezes, somente para as medidas estruturais. As soluções geralmente encontradas por parte do poder público têm sido as redes de drenagem, que simplesmente transferem a inundação de um ponto para outro a jusante na bacia sem que se avaliem os reais benefícios da obra. Estas ações de visão local atuam sobre o efeito e não sobre as causas do aumento da vazão, que são: o aumento das superfícies impermeáveis; aumento da densidade de drenagem (microdrenagem); redução da rugosidade; mudanças de geometria de cursos d'água naturais.

A tendência moderna na área de drenagem urbana, é a busca da manutenção das condições de pré-desenvolvimento atuando na fonte da geração do mesmo. Para tanto deve-se utilizar de dispositivos de acréscimo de infiltração e do aumento de retardo do escoamento.

Um tipo de dispositivo utilizado com este fim é o pavimento permeável, que é capaz de reduzir volumes de escoamento superficial e vazões de pico a níveis iguais ou até inferiores aos observados antes da urbanização, redução do impacto da qualidade da água e dos sedimentos.

Neste estudo são apresentadas a instalação experimental e as simulações utilizadas com o objetivo de analisar a eficiência de pavimentos permeáveis na redução de escoamento superficial, em comparação com solo compactado e também com pavimentos impermeáveis e semi-permeáveis.

\section{PAVIMENTO PERMEÁVEL}

Pavimento Permeável é um dispositivo de infiltração onde o escoamento superficial é desviado através de uma superfície permeável para dentro de um reservatório de pedras localizado sob a superfície do terreno (Urbonas e Stahre, 1993). Segundo Schueller (1987), os pavimentos permeáveis são compostos por duas camadas de agregados (uma de agregado fino ou médio e outra de agregado graúdo) mais a camada do pavimento permeável propriamente dito.

O escoamento infiltra rapidamente na capa ou revestimento poroso (espessura de 5 a $10 \mathrm{~cm}$ ), passa por um filtro de agregado de $1,25 \mathrm{~cm}$ de diâmetro e espessura de aproximadamente $2,5 \mathrm{~cm}$ e vai para uma câmara ou reservatório de pedras mais profundo com agregados de 3,8 a $7,6 \mathrm{~cm}$ de 
diâmetro. A capa de revestimento permeável somente age como um conduto rápido para o escoamento chegar ao reservatório de pedras. O escoamento, neste reservatório, poderá então ser infiltrado para o subsolo ou ser coletado por tubos de drenagem e transportado para uma saída. Assim, a capacidade de armazenamento dos pavimentos porosos é determinada pela espessura do reservatório de pedras subterrâneo (mais o escoamento perdido por infiltração para o subsolo).

Urbonas e Stahre (1993) classificam os pavimentos permeáveis basicamente em três tipos (Figura 1):

i. pavimento de concreto poroso;

ii. pavimento de asfalto poroso;

iii. pavimento de blocos de concreto vazados preenchidos com material granular, como areia ou vegetação rasteira, como grama.

A camada superior dos pavimentos porosos (asfalto ou concreto) é construída de forma similar aos pavimentos convencionais, mas com a retirada da fração da areia fina da mistura dos agregados do pavimento.

Os blocos de concreto vazados são colocados acima de uma camada de base granular (areia). Filtros geotêxteis são colocados sob a camada de areia fina para prevenir a migração da areia fina para a camada granular.

Urbonas e Stahre (1993) mencionam que não existem limitações para o uso do pavimento permeável, exceto quando a água não pode infiltrar para dentro do subsolo devido a baixa permeabilidade do solo ou se o nível do lençol freático for alto, ou ainda se houver uma camada impermeável que não permita a infiltração. Neste caso o pavimento permeável poderá funcionar como um poço de detenção, utilizando para isso uma membrana impermeável entre o reservatório e solo existente. O sistema de drenagem com tubos perfurados espaçados de 3 a $8 \mathrm{~m}$ deve completar este dispositivo nesta situação. O sistema deverá prever o esgotamento do volume num período de 6 a 12 horas. Há, igualmente, restrição quando a qualidade da água de infiltração levar à poluição de águas subterrâneas.

A utilização dos pavimentos permeáveis, em um contexto geral, pode proporcionar uma redução dos volumes escoados e do tempo de resposta da bacia para condições similares ou até mesmo, dependendo das características do subsolo, condições melhores que as de prédesenvolvimento, desde que seja utilizado racionalmente, respeitando seus limites físicos, e desde que seja conservado periodicamente (trimestral- mente) com uma manutenção preventiva, evitando assim o seu entupimento.

As principais limitações destes dispositivo podem ser:

- quando a água drenada é fortemente contaminada, haverá impacto sobre o lençol freático e o escoamento subterrâneo;

- falta de controle na construção e manutenção que podem entupir os dispositivos tornando-os ineficientes.

\section{DIMENSIONAMENTO DO PAVIMENTO PERMEÁVEL}

Equações - O dimensionamento envolve a determinação do volume drenado pela superfície ou por outra contribuinte que escoe para a área do pavimento. A precipitação é obtida com base no tempo de retorno escolhido e da curva intensidade, duração e freqüência do local.

Para o dimensionamento de um sistema de infiltração total (sem tubos de drenagem na parte superior do reservatório), o reservatório de pedras deve ser grande o suficiente para acomodar o volume do escoamento de uma chuva de projeto menos o volume de escoamento que é infiltrado durante a chuva. O volume de escoamento superficial gerado pela precipitação pode ser estimado através de:

$$
\mathrm{Vr}=\left(\mathrm{i}_{\mathrm{p}}+\mathrm{c}-\mathrm{i}_{\mathrm{e}}\right) \cdot \mathrm{t}_{\mathrm{d}}
$$

onde $\mathrm{Vr}$ é o volume de chuva a ser retido pelo reservatório (em $\mathrm{mm}), i_{p}$ é a intensidade máxima da chuva de projeto (em $\mathrm{mm} / \mathrm{h}), \mathrm{i}_{\mathrm{e}}$ é a taxa de infiltração do solo (em $\mathrm{mm} / \mathrm{h}), \mathrm{t}_{d}$ é o tempo de duração da chuva (em horas) e c um fator de contribuição de áreas externas ao pavimento permeável, que pode ser estimado pela equação:

$$
c=\frac{i_{p} \cdot A c}{A p}
$$

onde Ac é área externa de contribuição para o pavimento permeável e Ap é área de pavimento permeável.

A profundidade do reservatório de pedras do pavimento permeável é determinado por:

$$
H=\frac{V r}{f}
$$

onde $\mathrm{H}$ é a profundidade do reservatório de pedras (em $\mathrm{mm})$ e f é a porosidade do material. 


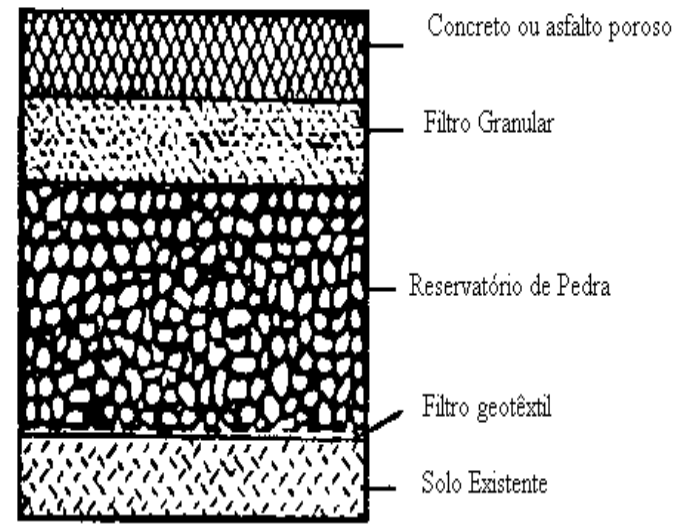

(i) e (ii) Concreto ou Asfalto Poroso

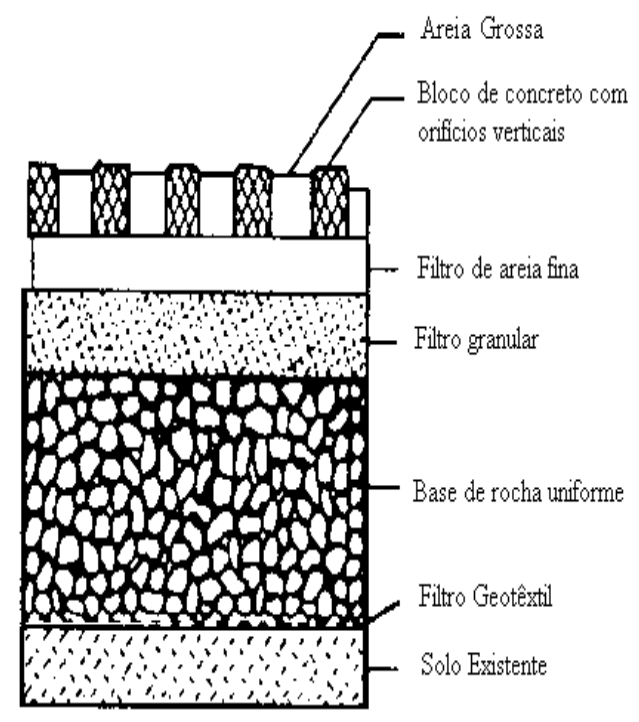

(iii) Blocos de Concreto Vazados

Figura 1. Pavimento permeável (Urbonas e Stahre, 1993). equação:

A porosidade pode ser determinada pela

$$
f=\frac{V_{L}+V_{G}}{V_{T}}
$$

onde $V_{L}$ é o volume de líquidos, $V_{G}$ é o volume de vazios e $\mathrm{V}_{\mathrm{T}}$ é o volume total da amostra.

Estimativa dos parâmetros - Os pavimentos permeáveis somente são viáveis para taxa de infiltração superior a $7 \mathrm{~mm} / \mathrm{h}$. Para a sua estimativa deve-se realizar uma sondagem a uma profundidade de 0,6 a 1,2 $\mathrm{m}$ abaixo do nível inferior do reservatório de pedras a fim de verificar o tipo de solo existente (já que tipos de solos com um percentual superior a $30 \%$ de argila ou $40 \%$ de silte e argila combinados não são bons candidatos para este tipo de dispositivo). A camada impermeável ou o nivel do lençol freático no período chuvoso deve estar pelo menos 1,2 m abaixo do pavimento.

Para determinar a profundidade do reservatório de pedras, é necessário selecionar o tipo de material a ser utilizado no mesmo. Schueller (1987) recomenda o uso de brita 3 ou 4 no reservatório de pedras.

Foram feitos alguns ensaios de porosidade para uma brita 3 (comercial) e chegou-se a valores de porosidade da ordem de 40 a $50 \%$. Desta for$\mathrm{ma}$, com os valores de porosidade e volume de água a reter pode-se estimar a profundidade do reservatório de pedras. Aconselha-se, por questões práticas, utilizar profundidade mínimas do reservatório de pedras de $15 \mathrm{~cm}$.

\section{INSTALAÇÃO EXPERIMENTAL}

O experimento, efetuado na área do Instituto de Pesquisas Hidráulicas (IPH) da Universidade Federal do Rio Grande do Sul (UFRGS), consistiu na simulação de chuvas sobre diferentes tipos de superfície.

As simulações de chuva têm por objetivo determinar as leis de infiltração e o escoamento superficial na escala pontual para relacioná-la posteriormente com a dinâmica da água em parcelas e bacias maiores. Elas fornecem um melhor conhecimento dos processos básicos da produção de escoamento em diversas situações, no espaço e no tempo, permitindo comparar a eficácia do uso dos pavimentos permeáveis em relação a outros tipos de coberturas na redução do volume de água de um escoamento superficial gerado por um determinado evento de chuva.

O simulador de chuvas utilizado nas simulações foi o aparelho concebido por Asseline e Valentin (1978). Segundo Silveira e Chevallier (1991), este simulador tem a capacidade de gerar precipitações com intensidades variáveis sobre uma parcela alvo de $1 \mathrm{~m}^{2}$. 
A água é bombeada a uma vazão constante até um aspersor fixado a um braço, cujo movimento pendular define a intensidade da chuva aspergida sobre a parcela de $1 \mathrm{~m}^{2}$. O dispositivo de aspersão é fixado no topo de uma torre metálica de aproximadamente $4 \mathrm{~m}$ de altura. As quatro faces laterais da torre são cobertas com tecido resistente para minimizar o efeito do vento sobre o jato do aspersor. O circuito hidráulico é composto de uma bomba elétrica e um tonel d'água, que alimenta o aspersor através de um conjunto de mangueiras. Dois manômetros, um colocado logo a jusante da bomba elétrica e outro no alto da torre, servem para controlar a pressão, que deve ser constante e compatível com a vazão do aspersor. Para realizar as medições na parcela de $1 \mathrm{~m}^{2}$, esta é isolada por um quadro metálico vazado cravado na superfície a ser avaliada. No lado que recebe o fluxo do escoamento superficial há pequenos furos (que devem estar posicionados ao nível do terreno) pelos quais a água atinge uma calha coletora que reúne todo o fluxo e o remete, por um tubo, à cuba de um linígrafo (Silveira e Chevallier, 1991).

\section{SUPERFÍCIES ESTUDADAS}

As superfícies escolhidas para execução dos ensaios de simulação de chuva foram (Figura 2):

- Solo compactado com declividade de 1 a $3 \%$;

- Pavimentos impermeáveis: uma parcela de concreto convencional de cimento, areia e brita, com declividade de 4\%;

- Pavimentos semi-permeáveis: uma parcela de superfície com pedras regulares de granito com juntas de areia, conhecidas por paralelepípedos, com declividade de $4 \%$; e outra parcela revestida com pedras de concreto industrializado tipo "pavi S" igualmente com juntas de areia, conhecida por blocket, com declividade de $2 \%$;

- Pavimentos permeáveis: uma parcela de blocos de concreto com orifícios verticais preenchidos com material granular (areia) com declividade de $2 \%$ e uma parcela de concreto poroso com declividade de $2 \%$.

\section{Solo compactado}

A parcela de solo compactado (Figura 2) foi instalada sobre uma antiga rua de chão batido (que hoje se encontra desativada), executada em um corte do terreno natural há mais de 40 anos atrás.
A simulação no solo compactado foi efetuada para se ter um parâmetro das condições de pré-urbanização do local de testes. É provável que o terreno escolhido tenha as suas condições naturais de infiltração modificadas, em função de ter havido um pré-adensamento por motivo do tráfego que existiu no passado. Este fato coincide com uma situação generalizada que ocorre nas áreas urbanas, onde o solo natural é alterado sofrendo uma compactação mecânica natural, além de misturas com outros materiais de diferentes granulometrias.

A parcela de solo compactado tinha declividade variando de 1 a $3 \%$ (declividade média de $2 \%$ ). A superfície apresentava-se coberta por vegetação rasteira típica da região. O solo é argiloso até a profundidade de $70 \mathrm{~cm}$ segundo classificação USDA (Cauduro e Dorfman, 1990). Após esta profundidade o solo está classificado como franco.

\section{Pavimento impermeável}

Foi necessário efetuar-se simulações de chuva sobre uma parcela impermeável para se ter um parâmetro de comparação de locais totalmente impermeabilizados, como passeios, estacionamentos de "shopping centers" e supermercados. A superfície escolhida para representar a parcela impermeável foi o pavimento de concreto de cimento, areia e brita (Figura 2), devido ao fato de tal superfície ser muito utilizada nos locais citados anteriormente e por ser de fácil execução.

O pavimento de concreto foi construído em um módulo de dimensões $3 \times 3 \mathrm{~m}$ e espessura entre 10 e $12 \mathrm{~cm}$, sendo isolada uma parcela de $1 \mathrm{~m}^{2}$ através de um quadro metálico chumbado no pavimento. A construção foi efetuada de modo que o pavimento ficasse no mesmo nível da rua.

\section{Pavimentos semi-permeáveis}

Foram utilizados dois tipos de pavimentos semi-permeáveis: blocos de concreto industrializado do tipo "Pavi S" (blockets) e paralelepípedos de granito (Figura 2). A escolha destes pavimentos ocorreu em função de que tais superfícies são muito utilizadas na região da grande Porto Alegre e por apresentarem uma boa taxa de infiltração de água por suas juntas de areia.

Os pavimentos de blocos de concreto e de paralelepípedos já existiam na área experimental, construídos para experimentos anteriores, sendo que a escavação de cada superfície foi feita de modo que a superfície ficasse no mesmo nível da rua e que as pedras ficassem confinadas lateralmente (Genz, 1994). 


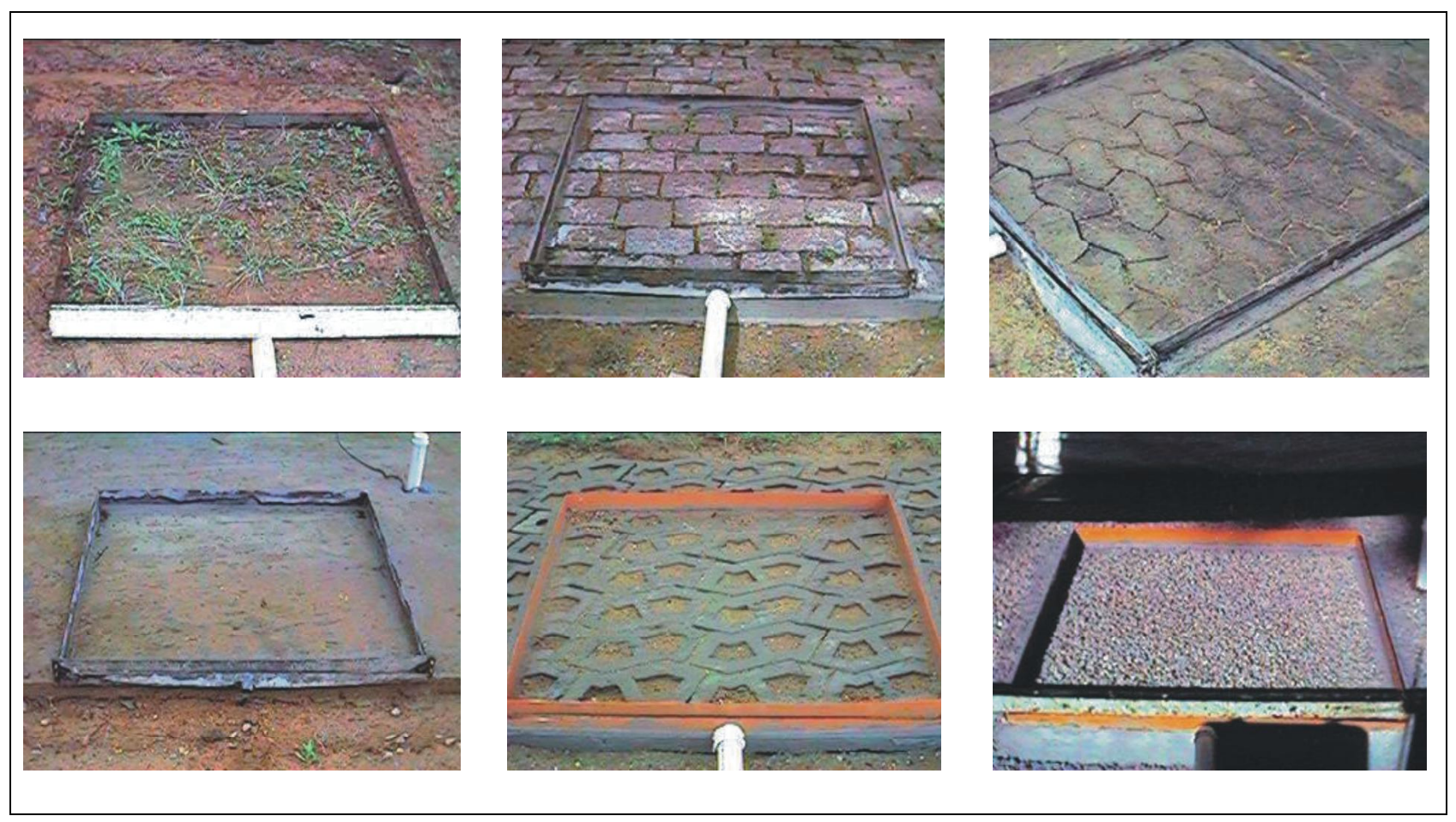

Figura 2. Pavimentos simulados.

As pedras interiores na parcela de $1 \mathrm{~m}^{2}$ de paralelepípedo têm um tamanho médio de $13 \times 18 \mathrm{~cm}$, em 7 linhas paralelas à face coletora. As juntas têm uma largura média de $1 \mathrm{~cm}$ e perfazem 6 linhas contínuas, paralelas à face coletora, com 6 juntas por cada linha de pedra. As pedras interiores da parcela de $1 \mathrm{~m}^{2}$ de blocos de concreto industrializados formam nove linhas no sentido paralelo à face coletora, possibilitando 8 linhas de junta, com cinco juntas por linha de pedra e juntas com espessura média de $4 \mathrm{~mm}$.

Antes de começar as simulações foi necessário executar uma limpeza em ambas as superfícies, pois apresentavam-se cobertas por vegetação rasteira do tipo capim. Esta vegetação indica a presença de matéria orgânica e sedimentos mais finos nas juntas de areia dos pavimentos $e$ possivelmente este material possa a vir reduzir a taxa de infiltração destas superfícies devido ao entupimento causado por estas partículas. Esta situação, mais uma vez, coincide com uma situação generalizada que ocorre a estes tipos de pavimentos, onde as partículas são carreadas para as juntas e o entupimento é inevitável.

\section{Pavimento permeável}

Foram utilizadas duas superfícies de pavimentos permeáveis: blocos de concreto industriali- zados e vazados do tipo "S" e uma parcela de concreto poroso (Figura 2).

No dimensionamento do reservatório de pedras foi utilizado o sistema de infiltração total, onde a única maneira da água sair do reservatório de pedras é através da infiltração para o subsolo. Foi adotada chuva de duração de $10 \mathrm{~min}$, com período de retorno de 5 anos. Utilizando-se a curva IDF do Posto Redenção, na cidade de Porto Alegre (Goldenfum et al., 1990), obtém-se a intensidade máxima de chuva igual a $111,9 \mathrm{~mm} / \mathrm{h}$, estimando-se, portanto, o volume a ser retido pelo reservatório em $17,5 \mathrm{~mm}$. Sendo a porosidade da brita 3 igual a $46 \%$, obteve-se uma altura de reservatório de $37,3 \mathrm{~mm}$. Esta profundidade é baixa porque foi utilizada uma chuva com período de retorno relativamente pequeno e por não haver áreas de contribuição externas para o pavimento permeável. Como seria impossível a execução de uma camada de brita com esta espessura, já que a própria dimensão da brita ultrapassaria aquela altura, resolveu-se adotar uma profundidade de $150 \mathrm{~mm}$, correspondente à mínima espessura verificada em projetos semelhantes.

Blocos Vazados - O módulo de blocos vazados foi construído para que a superfície pronta ficasse no mesmo nível da superfície e os blocos ficassem confinados lateralmente. A escavação foi executada em uma área de $2,0 \times 2,0 \mathrm{~m}$, com pro- 
fundidade de $20 \mathrm{~cm}$. No centro desta foi novamente escavado no terreno uma abertura com área de $1,0 \times 1,0$ e espessura de $15 \mathrm{~cm}$, com a função de futuramente ser o reservatório de pedras dos pavimentos permeáveis. O solo, na base da abertura, não foi compactado para evitar uma redução na capacidade de infiltração do terreno. $\mathrm{Na}$ base da abertura de 1,0 x 1,0 foi colocado um filtro geotêxtil com a finalidade de separar o agregado graúdo do solo e assim evitar a migração do solo para o reservatório de pedras, quando este estiver na condição de enchimento. O vão de $1,0 \times 1,0 \mathrm{~m}$ foi preenchido com brita 3 de granito até o topo, perfazendo uma espessura final de agregado igual a $15 \mathrm{~cm}$. Após a compactação manual do agregado, novamente foi colocado um tecido geotêxtil sobre a camada de agregado com a finalidade de prevenir a migração da areia média da camada superior para dentro do reservatório de pedras. Uma camada de $10 \mathrm{~cm}$ de areia média foi colocada sobre todo o módulo de $2,00 \times 2,00$. Por fim, os blocos vazados foram assentados sobre a areia e as juntas e os orifícios dos blocos de concreto foram preenchidos com areia. A declividade final da parcela ficou em $2 \%$.

Concreto poroso - O pavimento de concreto poroso (também denominado concreto sem finos) foi executado seguindo o traço 1:6 da Tabela 1 , com brita 1 (comercial) de granito. O concreto sem finos deve ser pouco adensável e a vibração aplicada por períodos muito curtos, para que a pasta de cimento não escorra para o fundo. Também não se recomenda o adensamento com soquetes pois podem resultar massas específicas localizadas elevadas. Para o concreto sem finos não existem ensaios de trabalhabilidade; somente é possível avaliar visualmente se a camada de revestimento das partículas é adequada. Os concretos sem finos têm baixo valor de coesão; por isso as formas devem ser mantidas até que se tenha desenvolvido uma resistência suficiente. A cura úmida é importante, especialmente em climas secos e com ocorrência de vento devido às pequenas espessuras da pasta de cimento (Neville, 1982).

A construção foi semelhante à dos blocos vazados com a única diferença no revestimento superficial, que foi o concreto poroso com espessura de $15 \mathrm{~cm}$.

\section{SIMULAÇÃO DAS SUPERFÍCIES}

Foram efetuadas simulações da chuva de projeto (duração de $10 \mathrm{~min}$, período de retorno de 5 anos e intensidade de $111,9 \mathrm{~mm} / \mathrm{h}$ ) sobre as parce- las de solo compactado, pavimento impermeável (concreto), pavimentos semi-permeáveis (blocos de concreto e paralelepípedos) e pavimento permeável (blocos de concreto vazados). O resumo dos resultados das simulações pode ser observado na Tabela 2.

O coeficiente de escoamento é obtido pela razão entre a chuva e o escoamento totais. A umidade do solo antes da simulação de chuva foi calculada a partir da calibração da curva de umidade em relação à contagem de sonda de nêutrons e está referenciado à profundidade de $50 \mathrm{~cm}$.

Os escoamentos foram discretizados em intervalos de 30 segundos e, por apresentarem grande variabilidade em decorrência desta discretização, passaram por um filtro de média móvel dos 3 primeiros elementos. Em função deste filtro os hidrogramas começam a decair antes dos 10 minutos (tempo de duração da simulação). A Figura 3 apresenta os escoamentos superficiais observados nas simulações.

Nas simulações no módulo de concreto observou-se escoamento superficial imediatamente após o início da chuva. O coeficiente de escoamento neste pavimento foi $44 \%$ superior ao da simulação no solo compactado. Este coeficiente mostra que praticamente toda a chuva gerou o escoamento coletado na cuba do linígrafo. A diferença $(5 \%)$ entre os volumes precipitado e escoado se deu devido à parcela de água que fica retida no quadro metálico e a uma pequena absorção no concreto, não sendo registrada pelo linígrafo. Ao término da simulação, o tempo de esvaziamento foi maior que o das outras superfícies. Isto ocorreu devido ao armazenamento de água nas irregularidades da superfície do concreto e também pelo acúmulo de água dentro do quadro metálico, causado por falta de capacidade de vazão do tubo que saía da face coletora. Este resultado reforça a necessidade de utilização de dispositivos de redução do escoamento superficial, uma vez que o excesso gerado em áreas cobertas com este tipo de pavimento (ou outros pavimentos impermeáveis) contribui diretamente para o crescimento das cheias urbanas.

Nas simulações nas superfícies semipermeáveis o escoamento superficial também começa imediatamente após o início da chuva, mas os volumes gerados são inferiores aos do concreto. $\mathrm{Na}$ simulação no módulo de paralelepípedos, o coeficiente de escoamento é, inclusive, menor do que o observado no solo compactado: nos blocos de concreto observou-se coeficiente de escoamento $22 \%$ superior ao do solo compactado; nos paralelepípedos foi registrado coeficiente de escoamento $11 \%$ menor que o do solo compactado. Pode-se concluir que, embora não haja garantia de manu- 
Tabela 1. Característica dos concretos sem finos para agregado de 9,5 a $19 \mathrm{~mm}$. (Mclntosh, Botton e Muir, 1956 apud Neville, 1982).

\begin{tabular}{cccc}
\hline $\begin{array}{c}\text { Relação Cimen- } \\
\text { to/agregado } \\
\text { em volume }\end{array}$ & $\begin{array}{c}\text { Relação } \\
\text { Água/cimento } \\
\text { em masas }\end{array}$ & $\begin{array}{c}\text { Massa } \\
\text { Específica } \\
\left(\mathrm{Kg} / \mathrm{m}^{3}\right)\end{array}$ & $\begin{array}{c}\text { Resistência a } \\
\text { Compressão } \\
\text { 28 dias - MPa }\end{array}$ \\
\hline $1: 6$ & 0,38 & 2020 & 14 \\
$1: 7$ & 0,40 & 1970 & 12 \\
$1: 8$ & 0,41 & 1940 & 10 \\
$1: 10$ & 0,45 & 1870 & 7 \\
\hline
\end{tabular}

Tabela 2. Resultados das simulações de chuva nas superfícies simuladas.

\begin{tabular}{lcccccc}
\hline & $\begin{array}{c}\text { Solo } \\
\text { Compactado }\end{array}$ & Concreto & $\begin{array}{c}\text { Bloco de } \\
\text { Concreto }\end{array}$ & $\begin{array}{c}\text { Paralele- } \\
\text { pípedo }\end{array}$ & $\begin{array}{c}\text { Concreto } \\
\text { Poroso }\end{array}$ & $\begin{array}{c}\text { Blocos } \\
\text { Vazados }\end{array}$ \\
\hline Data & $03 / 06 / 98$ & $28 / 10 / 98$ & $29 / 07 / 98$ & $13 / 10 / 98$ & $13 / 04 / 99$ & $27 / 01 / 99$ \\
Hora Início & $14 \mathrm{~h} 06 \mathrm{~min}$ & $15 \mathrm{~h} 15 \mathrm{~min}$ & $15 \mathrm{~h} 20 \mathrm{~min}$ & $11 \mathrm{~h} 20 \mathrm{~min}$ & $14 \mathrm{~h} 55 \mathrm{~min}$ & $10 \mathrm{~h} 08 \mathrm{~min}$ \\
Intensidade simulada $(\mathrm{mm} / \mathrm{h})$ & 112 & 110 & 116 & 110 & 120 & 110 \\
Chuva total $(\mathrm{mm})$ & 18,66 & 18,33 & 19,33 & 18,33 & 20,00 & 18,33 \\
Escoamento total $(\mathrm{mm})$ & 12,32 & 17,45 & 15,00 & 10,99 & 0,01 & 0,5 \\
Coeficiente de escoamento & 0,66 & 0,95 & 0,78 & 0,60 & 0,005 & 0,03 \\
Umidade inicial do solo $\left(\mathrm{cm}^{3} / \mathrm{cm}^{3}\right)$ & 32,81 & 32,73 & 32,71 & 32,72 & 0,329 & 32,24 \\
\hline
\end{tabular}

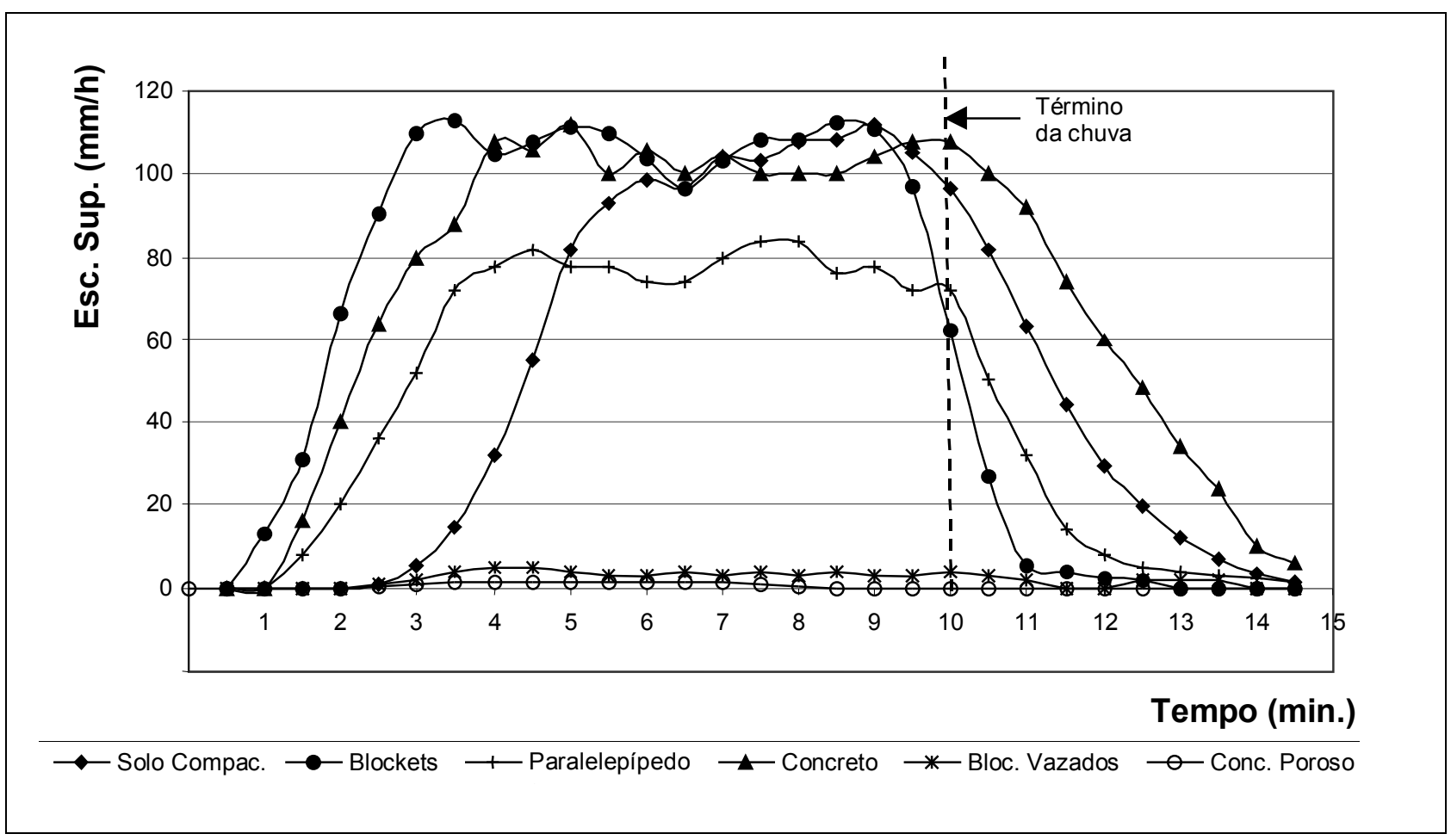

Figura 3. Escoamento superficial observado nas diversas superfícies ensaiadas. 
tenção das condições de pré-desenvolvimento, há uma significativa redução em comparação com o escoamento gerado em superfícies impermeáveis. Seu uso em áreas urbanas, embora possa acarretar aumento de escoamento superficial em relação a áreas ainda não ocupadas, pode contribuir para o controle da geração de escoamento superficial quando instalados em substituição a pavimentos impermeáveis.

É importante ressaltar que se observou um volume de escoamento gerado no pavimento de paralelepípedo bastante inferior ao dos blocos de concreto. As possíveis causas para tal diferença são:

- a área da junta da parcela de blocos de concreto é menor do que a de paralelepípedos, o que se traduz em menor capacidade de infiltração. Os blocos de concreto têm uma junta de aproximadamente $4 \mathrm{~mm}$, perfazendo uma área média de juntas de $5 \%$ da área da parcela, enquanto que o pavimento de paralelepípedos têm uma junta de aproximadamente $10 \mathrm{~mm}$, correspondendo a uma área média de $10 \%$ da área da parcela;

- o pavimento de paralelepípedo é mais irregular que o dos blocos de concreto possuindo mais depressões nas juntas e tendo, consequentemente, mais capacidade de retenção de água;

- é possível ter ocorrido algum vazamento de água através das laterais do quadro metálico da parcela de paralelepípedo, reduzindo o escoamento superficial medido e provocando uma taxa de infiltração (calculada por balanço hídrico da parcela) bem maior que a da realidade.

$\mathrm{Na}$ simulação de chuva nos pavimentos permeáveis praticamente não ocorreu escoamento superficial. O pequeno escoamento gerado foi provavelmente devido ao arremate de concreto junto à face coletora do quadro metálico. Foram efetuadas três simulações de chuva nos blocos vazados e para as três simulações o resultado foi o mesmo (apenas $0,5 \mathrm{~mm}$ de escoamento gerado). Já na parcela de concreto poroso, nos três ensaios realizados na parcela o coeficiente de escoamento não passou de 0,01. Observa-se, portanto, que estes pavimentos não apenas mantém as condições originais de geração de escoamento superficial, mas podem reduzir estes valores a praticamente zero, dependendo das condições antecedentes e da capacidade do reservatório de pedras. Com isto, mostram ser dispositivos altamente recomendados para o controle dos volumes escoados. Levando em conta seu baixo poder de suporte e problemas de manutenção, recomenda-se que estes pavimentos sejam utilizados em calçadas e em estacionamentos para veículos leves em áreas de "shopping centers" e grandes supermercados.

\section{ANÁLISE DO CUSTO}

O custo obtido para a implantação de cada pavimento pode ser visto na Tabela 3 . Todos os componentes de material e mão-de-obra foram retirados de REGISUL (1999). Nos custos de mãode-obra foram incluídos todos os custos indiretos gastos com encargos sociais.

O uso de pavimentos permeáveis pode eliminar a necessidade de caixas de captação e tubos de condução da água, pois o dispositivo praticamente não gera escoamento quando as condições locais permitem sua adoção prevendo-se infiltração plena no solo.

Além dos custos de implantação dos pavimentos permeáveis existe o custo de manutenção que consiste na limpeza dos poros dos pavimentos porosos (concreto poroso) com jatos d'água e máquinas de aspiração de sedimentos e poeiras. Estes custos não foram estimados devido à inexistência de empresas especializadas na manutenção deste tipo de dispositivo no país. No entanto, para se ter uma idéia o custo médio gasto em um manutenção nos Estados Unidos é na ordem de 1 a $2 \%$ do custo de implantação do dispositivo.

\section{CONCLUSÕES}

Nas simulações efetuadas no módulo de pavimento impermeável praticamente toda chuva gera escoamento superficial, com acréscimo de $44 \%$ no coeficiente de escoamento, em comparação com a simulação no solo compactado, mostrando a potencialidade de crescimento das cheias urbanas em função de uma utilização intensa deste tipo de cobertura.

As simulações nas superfícies semipermeáveis apresentaram escoamento superficial inferior ao do concreto: nos blocos de concreto observa-se crescimento de $22 \%$ no coeficiente de escoamento e nos paralelepípedos é registrada queda de $11 \%$ neste coeficiente, sempre em comparação com o solo compactado. O seu uso em áreas urbanas pode contribuir para o controle da geração de escoamento superficial quando instalados em substituição a pavimentos impermeáveis.

$\mathrm{Na}$ simulação de chuva no pavimento permeável praticamente não ocorreu escoamento 
Tabela 3. Custo de implantação dos pavimentos.

\begin{tabular}{lc}
\hline Tipo de pavimento & Custo unitário $\left(\mathrm{m}^{2}\right)$ \\
\hline Blocos de concreto & 10,10 \\
Paralelepípedo & 16,74 \\
Concreto impermeável & 13,14 \\
Blocos vazados & 18,22 \\
Concreto poroso & 19,06 \\
\hline
\end{tabular}

superficial. Sugere-se, por questões de resistência estrutural e de manutenção, que estes pavimentos sejam utilizados em estacionamentos para veículos leves, especialmente em áreas de "shopping centers" e grandes supermercados, uma vez que eles mostram ser dispositivos altamente recomendados para o controle dos volumes escoados, apresentando inclusive redução em comparação com as condições de pré-desenvolvimento.

Neste estudo não foi analisada a capacidade de redução da carga de poluentes pelo uso de pavimentos permeáveis, mas este também é um dos grandes benefícios deste tipo de pavimento.

As limitações identificadas foram quanto a necessidade de manutenção e o maior custo por $\mathrm{m}^{2}$. O aumento do custo específico pode ser compensado pela redução da drenagem resultante da área, já que grande parte do volume se infiltrará.

Deve-se ressaltar também, que o pavimento apresentará uma melhoria importante para inundações freqüentes e de alto risco, no entanto quando o reservatório estiver cheio para grandes volumes de precipitação o pavimento poderá apresentar uma menor ineficiência do que apresentada nos experimentos.

\section{AGRADECIMENTOS}

Agradecemos o suporte financeiro provido através dos projetos de pesquisa "Avaliação e controle dos impactos ambientais decorrentes da urbanização" (PRONEX - MCT, CNPq, FINEP) e "Controle de cheias devido a urbanização" (RECOPE/REHIDRO - Subrede 3 - MCT, FINEP). Agradecemos, também, o auxílio prestado na execução dos experimentos pelo bolsista de iniciação científica André Mitto e pelos hidrotécnicos Paulo Édson Marques e Luiz Gregório Raupp.

\section{REFERÊNCIAS}

ASSELINE, J. e VALENTIN, C. (1978) "Construction et mise au point d'un infiltròmetre à aspersion" Cah.
ORSTOM, série Hydrology, Paris, Vol. 15, n. 4, p. 321-50.

CAUDURO, F. A., DORFMAN, R. (1990) "Manual de ensaios de laboratório e de campo para irrigação e drenagem" Porto Alegre, PRONI, IPH/UFRGS, $216 p$.

GENZ, F. (1994) "Parâmetros para a previsão e controle de cheias urbanas" Porto Alegre, UFRGS - Curso de Pós-Graduação em Recursos Hídricos e Saneamento Ambiental. D 180. Dissertação de Mestrado.

GOLDENFUM, J. A., CAMAÑO, B., SILVESTRINI, J. (1990) "Chuvas Intensas em Porto Alegre Determinação de Curvas I-D-F" Porto Alegre, IPH/UFRGS, 26p.

NEVILLE, A. M. (1982) "Properties of Concret" (Português) Propriedades do Concreto. São Paulo, PINI. XVI, 738p. IL.

REGISUL discriminada (1999) "Listagem discriminada de composições de serviço" Porto Alegre. Março.

SCHUELLER, T. (1987) "Controlling Urban Runoff: $A$ Practical Manual for Planning and Designing Urban BMPs" Washington, metropolitan Washington Council of Governments.

SILVEIRA, A. L. L. e CHEVALLIER, P. (1991) "Primeiros Resultados sobre Infiltração em Solo Cultivado Usando Simulação de Chuvas (Bacia do rio Potiburu, RS)" In: Simpósio Brasileiro de Recursos Hídricos, 9, 1991, Rio de Janeiro. Anais. Rio de Janeiro: ABRH/APRH. 4v. v. 1, p. 213-21.

URBONAS, B. e STAHRE, P. (1993) "Stormwater Best Management Practices and Detention" Prentice Hall, Englewood Cliffs, New Jersey, 450p.

\section{Analysis of Permeable Surfaces in Overland Flow Control}

\section{ABSTRACT}

Porous pavements are used in urban areas in order to reduce the overland flow as well as to improve the water quality and groundwater recharge recovery.

In this paper an evaluation of the porous pavements efficiency in the reduction of overland flow is presented. Experimental simulations using a rainfall simulator were performed over $1 \mathrm{~m}^{2}$ parcels, with five different types of urban soil pavements: a) natural soil; b) concrete pavement; c) granite stones; d) concrete S-shaped blocks; e) and concrete garden blocks.

A comparative analysis of the behaviour of the porous pavements and other surfaces made it possible to verify the reduction of overland flow and provided elements for the selection of these devices in different urban area projects. 